\title{
Forbes albright syndrome: galactorrhea-amenorrhea associated with a pituitary tumour: a case report
}

\begin{abstract}
Forbes Albright syndrome is a hyperprolactinemia syndrome characterised by galactorrhea and amenorrhea associated with a pituitary tumour. Here we report a case of 30 years female who was admitted with menstrual irregularities for 4 months, galatorrhea and headache with recurrent episodes of loss of consciousness for 3 months. Her serum prolactin level was highly raised. MRI brain (plain plus contrast) showed enlarged pituitary gland- pituitary macroadenoma. She was diagnosed as a case of Forbes Albright Syndrome and was treated with Tablet Cabergoline. With the medication, size of her tumour markedly reduced and symptoms resolved as she was followed up after 3 months.
\end{abstract}

Keywords: hyperprolactinemia, pituitary macroadenoma, cabergoline, forbes albright syndrome, galactorrhea, amenorrhea, tumour

\author{
Volume 8 Issue I - 2021
}

\author{
Rupak Chatterjee,' Prantiki Halder,' \\ Sudeshna Mallik, ${ }^{3}$ Bibhuti Saha ${ }^{4}$ \\ 'Post Graduate Trainee (PGT) MD Tropical Medicine, School Of \\ Tropical Medicine, WBUHS, India \\ ${ }^{2}$ Tutor, Department of Tropical Medicine, School of Tropical \\ Medicine, WBUHS, India \\ ${ }^{3}$ Associate Professor, Department of Tropical Medicine, School \\ of Tropical Medicine, India \\ ${ }^{4}$ Professor, Department of Tropical Medicine, School of Tropical \\ Medicine, India
}
Correspondence: Rupak Chatterjee, Post Graduate Trainee (PGT) MD Tropical Medicine, School Of Tropical Medicine, West Bengal University Of Health Sciences (WBUHS), Kolkata, West Bengal, India, Tel 6290I56807,
Email rupakchatterje95@gmail.com

Received: December 16, 2020 | Published: February 22, 2021

\section{Background}

Prolactinoma is the most common pituitary adenoma ${ }^{1}$ which causes menstrual irregularities, infertility and galactorrhea in women. ${ }^{2}$ Forbes et al., presented the findings in fifteen non-acromegalic women who had persistent lactation and amenorrhea associated with low urinary FSH excretion. Seven of them had pituitary tumors. They suggested that the patients with these syndromes manifest overproduction of prolactin in pituitary. ${ }^{3}$ So presence of the clinical features of amenorrhea, galactorrhea accompanied with laboratory value of serum prolactin being much high should suggest a clinician to suspect presence of pituitary adenoma-prolactinoma.

\section{Case}

A 30 years female presented with complaints of recurrent loss of consciousness, headache and galactorrhea for last 3 months. She was normotensive, non-diabetic. There was no history of convulsions or vomiting. Regarding her menstrual history, she complained of irregular menstrual cycles-amenorrhea for last 4 months.

On Clinical examination-general survey and systemic examination, there was no significant abnormality noted except for milk secretion present in both breasts.

She was Para $\mathrm{P}_{2+0}$ i.e she has 2 children-both delivered by normal delivery, last childbirth being 7 years back. As she was having amenorrhea for 4 months, she had consulted Gynecologist. She was investigated and found that her serum Prolactin level was high-more than $200 \mathrm{ng} / \mathrm{ml}$ and her TSH was $2.54 \mathrm{mIU} / \mathrm{ml}$ (WNL). Her routine blood investigations, USG W/A, Chest X-ray were WNL.

As she was having headache and episodes of loss of consciousness, brain imaging and EEG were done. EEG was normal.

MRI Brain $(\mathrm{P}+\mathrm{C})$ showed pituitary gland enlarged with convex superior margin. Enlarged pituitary measured about $11 \mathrm{~mm}$ in $\mathrm{AP}$,
$14 \mathrm{~mm}$ in lateral and $11 \mathrm{~mm}$ in cranio-caudal dimensions. Post contrast study showed enhancement there. Infundibulum was central. Radiologist gave impression that MRI findings are suggestive of pituitary macroadenoma.

She was referred to neurology and endocrinology. Endocrinologist gave impression that the pituitary mass was likely macroprolactinoma (densely granulated cell type). And they advised Tab Cabergoline 1 tablet once daily for 2 days in a week and to review after 3 months with serum prolactin and MRI reports. Neurologist also opined the same and suggested for Psychiatry referral for her episodes of loss of consciousness (pseudoseizure). Psychiatrist diagnosed as her having psychogenic non-epileptic seizures as she complained of frequent episodes of unresponsiveness, lasting upto $4 \mathrm{hrs}$ during which patient could hear everything but cannot move or respond. They prescribed Escitalopram and Clonazepam tablets. Ophthalmology referral was done to rule out any visual field abnormality although the mass was away from optic chiasma and patient didn't have any visual symptoms.

Patient was discharged with Tablet Cabergoline $0.5 \mathrm{mg} 1$ tab twice weekly to continue and tab Escitalopram and clonazepam and advised to review after 3 months.

When patient came for follow up after 3 months, her symptoms had resolved. Serum prolactin level (measured by electrochemiluminescence assay) was $0.301 \mathrm{ng} / \mathrm{ml}$ [ref range for nonpregnant women being 4.79-23.3 ng/ml]. Her repeat MRI Brain $(\mathrm{P}+\mathrm{C})$ showed slightly prominent pituitary fossa with a small hypointense lesion-possibility of it being a very small adenoma. She was rereferred to Endocrinology department where was advised to continue Tablet Cabergoline $0.25 \mathrm{mg} 1$ tab twice weekly and review every 3 monthly with serum prolactin reports at their department.

Thus with Cabergoline, the symptoms of hyperprolactinemia resolved and the tumour size markedly regressed Figures 1-4. 


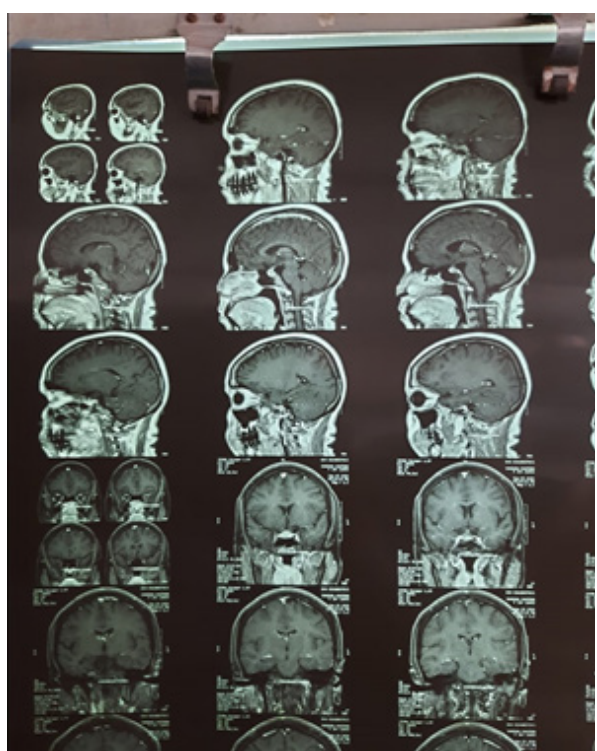

Figure I MRI brain of the patient.

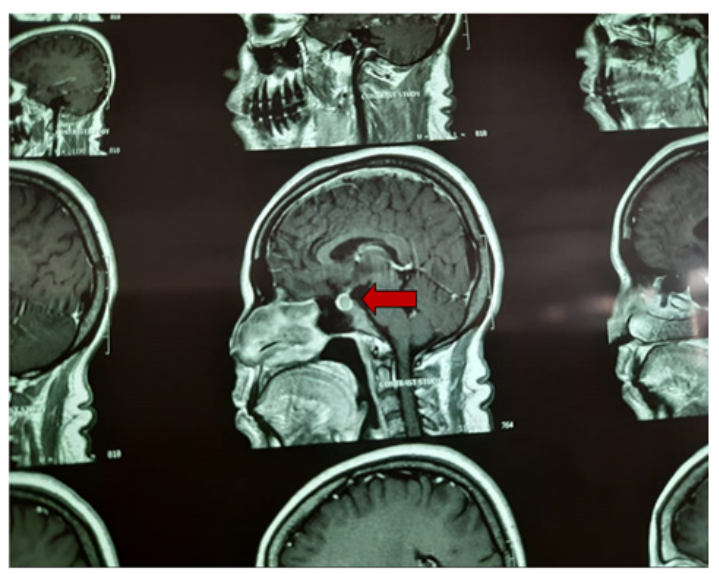

Figure 2 Closer section of the MRI brain section showing the pituitary macroadenoma-prolactinoma.

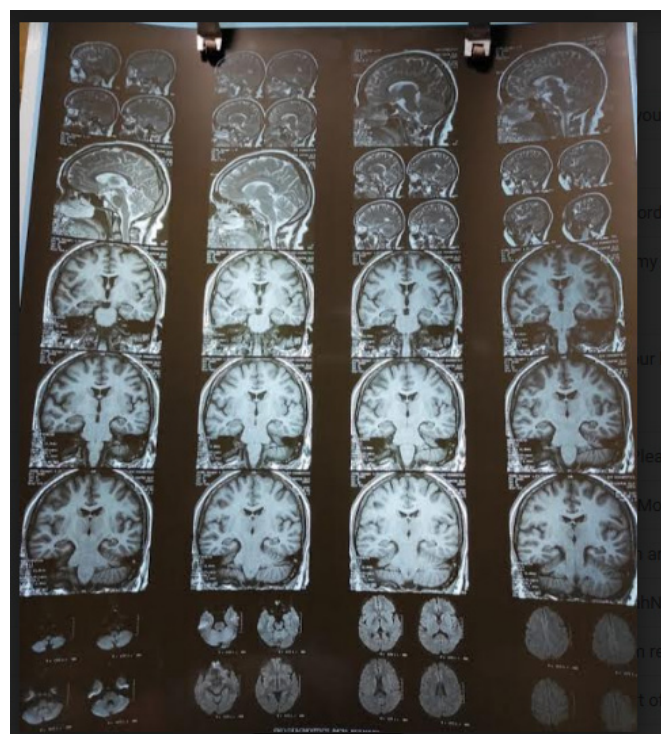

Figure $3 \mathrm{MRI}$ brain at follow-up at 3 months-showing mild prominent pituitary fossa-with possibility of a small adenoma.

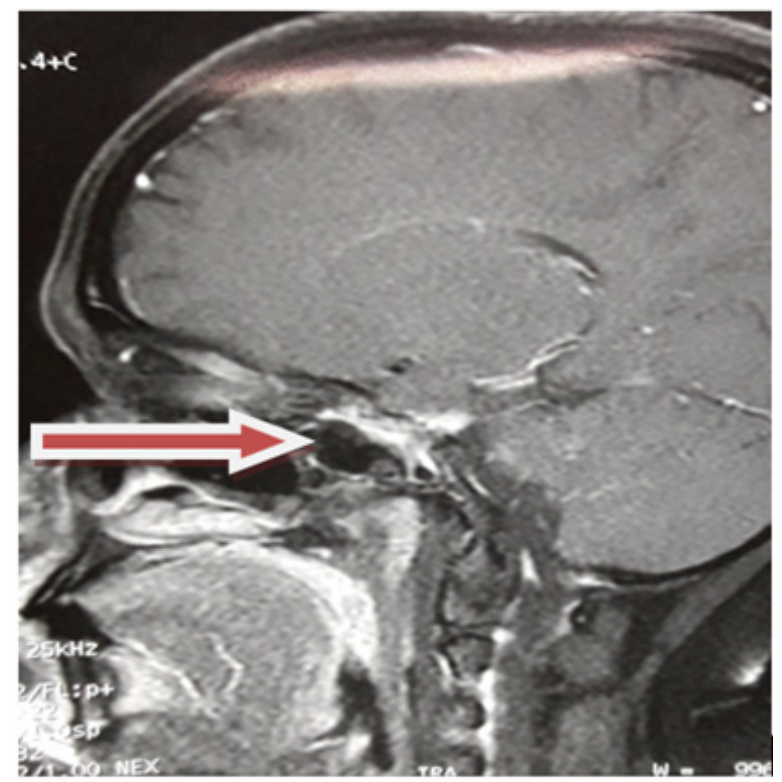

Figure 4 Follow-up MRI closer views showing slightly prominent pituitary fossa with convex superior surface.

\section{Discussion}

In Prolactin secreting macroadenomas, goals of therapy are to decrease tumour size, improve visual field defects if any and to improve sexual function. ${ }^{4}$ Dopamine agonists are used for treatment as they are able to achieve the above goals. ${ }^{5,6}$ In comparison to bromocriptine, cabergoline has fewer side effects and more benefits in normalizing prolactin levels. ${ }^{7}$ Studies show that cabergoline is safe and well-tolerated. ${ }^{4}$

One of the main regulators of the production of prolactin from the pituitary gland is Dopamine. Dopamine inhibits prolactin secretion via dopamine D2 receptors i.e; the secretion of prolactin by anterior pituitary is mainly under hypothalamic inhibitory control exerted through release of dopamine by tubero-infundibular neurons. ${ }^{8}$ Cabergoline is a long-acting dopamine receptor agonist with a high affinity for D2 receptors.

Galactorrhea occurs in increased prolactin levels due to direct physiologic effects of prolactin on breast epithelial cells; high prolactin levels inhibits $\mathrm{GnRH}$ (gonadotropin-releasing hormone) and interferes with normal production of hormones like estrogen and progesterone thus affecting ovulation adversely accounting for menstrual abnormality-amenorrhea.

Headache is reported in pituitary tumours and is related to tumour size and dural traction-stimulation of afferent pain sensitive fibers innervating the dura mater within the sella turcica leads to pain in form of headache. ${ }^{9}$

Cabergoline, being D2 receptor agonist thus results in decreasing prolactin secretion with normalization of symptoms due to hyperprolactinemia. As hyperprolactinemia is one of the causes of amenorrhea; a woman presenting with amenorrhea, galactorrhea, headache like symptoms should lead a clinician to investigate for so as to rule out a pituitary macroadenoma so that early initiation of therapy can provide benefit as was in our reported case. 


\section{Consent}

Informed consent was taken from patient.

\section{Acknowledgments}

None.

\section{Conflicts of interest}

The authors declare that there are no conflicts of interest.

\section{Funding}

None.

\section{References}

1. Mindermann T, Wilson CB. Age-related occurrence of pituitary adenomas. Clin Endocrinol (Oxf). 1999;41(3):359-364.

2. Gomez F, Reyes FI, Faiman C. Non puerperal galactorrhea and hyperprolactinemia. Clinical Findings, endocrine features and therapeutic responses in 56 cases. Am J Med. 1997;62(5):648-660.
3. Takatani O, Kumaoka S, Sakauchi N, et al. A case report of pituitary tumour presenting as forbes albright syndrome: determination of pituitary prolactin content. Endocrinol Jpn.1967;14(2):95-100.

4. Rahmanian M, Meybodi HA, Larijani B, et al. Giant prolactinoma: case report and review of literature. J Diabetes Metab Disord. 2013;12(1):3.

5. Verheist J, Abs R, Maiter D, et al. Cabergoline in treatment of hyperprolactinemia: a study in 455 patients. $J$ Clin Endocrinol Metab. 1999;84(7):2518-2522.

6. Shiman I, Benbassat C, Hadani M. Effectiveness of long term cabergoline treatment for giant prolactionoma: study of $12 \mathrm{men}$. Eur J Endocrinol. 2007;156(2):225-231.

7. Webster J, Piscitelli G, Polli A, et al. A comparison of cabergoline and bromocriptine in the treatment of hyperprolactinemic amenorrhea. $N$ Engl J Med. 1994;331(14):904-909.

8. Majumdar A, Mangal NS. Hyperprolactinemia. J Hum Reprod Sci. 2013;6(3):168-175.

9. Gondim JA, de Almeida JPC, de Albuquerque LAF, et al. Headache associated with pituitary tumors. J Headache Pain. 2009;10(1):15-20. 